\title{
Benefícios das Intervenções Assistidas por Animais para estudantes com alteração de linguagem verbal
}

\author{
Benefits of Animal Assisted Intervention \\ for students with verbal language disorders
}

\author{
Los Beneficios de las Intervenciones \\ Asistidas por Animales para estudiantes \\ con trastornos del lenguaje verbal
}

\author{
Fernanda Celeste Sánchez Weber* (D) \\ Dayane Stephanie Potgurski* (D) \\ Camilla Fernandes Diniz** (D) \\ Maria Beatriz Paludo Pizzolotto* (D) \\ Luana Zimmer Sarzi* (D) \\ Renata Gomes Camargo* (D)
}

\section{Resumo}

Introdução: As Intervenções Assistidas por Animais- IAA- com a mediação de cães compreendem atividades com fins terapêuticos e/ou educacionais, nas quais o cachorro é o principal mediador. Objetivo: Apresentar e analisar os resultados parciais das atividades desenvolvidas em um Projeto de Pesquisa e de Extensão, realizado no Colégio de Aplicação da Universidade Federal de Santa Catarina- CA/ UFSC, evidenciando os benefícios das IAA com a mediação de cães, no processo de desenvolvimento e aprendizagem, sobretudo da linguagem verbal (fala, leitura e escrita) para os estudantes participantes. Método: Seguiu-se a abordagem qualitativa da pesquisa e realizou-se a Análise de Conteúdo ${ }^{1}$ dos registros em diário de campo das atividades desenvolvidas. Resultados: São apresentados os resultados de três ações

* Universidade Federal de Santa Catarina, Florianópolis, SC, Brasil.

** Colégio Santa Terezinha, Florianópolis, SC, Brasil.

Contribuição dos autores:

FCSW: Concepção do estudo; Coleta de dados; Esboço do artigo.

DSP: Concepção do estudo; Metodologia; Coleta de dados; Esboço do artigo; Revisão crítica.

CFD: Metodologia; Coleta de dados; Esboço do artigo.

MBPP: Metodologia; Esboço do artigo.

LZS: Concepção do estudo; Metodologia; Coleta de dados; Esboço do artigo; Revisão crítica; Orientação.

RGC: Concepção do estudo; Metodologia; Coleta de dados; Esboço do artigo; Revisão crítica; Orientação.

E-mail para correspondência: Dayane Stephanie Potgurski - dayanepotgurski@gmail.com

Recebido: 06/10/2020

Aprovado: 22/02/2021 
realizadas no projeto durante o primeiro semestre de 2019. A análise dessas atividades demonstrou que foram favorecidas as habilidades relacionadas à linguagem verbal dos estudantes. Conclusão: Considerase que no decorrer do projeto, os participantes das IAA com a mediação de cães vêm demonstrando melhora nas aprendizagens, bem como aperfeiçoamento nas habilidades de fala, leitura e escrita.

Palavras-chave: Terapia Assistida com Animais; Desenvolvimento da Linguagem; Aprendizagem.

\section{Abstract}

Introduction: The Animal Assisted Intervention with the mediation of dogs comprises activities for therapeutic and / or educational purposes, in which the dog is the main mediator. Objective: To present and analyze the partial results of the activities developed in a Research and Extension Project, carried out at the Colégio de Aplicação da Universidade Federal de Santa Catarina- CA/UFSC, showing the benefits of Animal Assisted Intervention with the mediation of dogs in the process of development and learning, especially of the verbal language (speaking, reading and writing) for participating students. Method: The qualitative research approach was followed and Content Analysis ${ }^{1}$ was carried out on the records in the daily field of the activities developed. Results: The results of three actions carried out in the project during the first semester of 2019 are presented. The analysis of these activities showed that the students' verbal language skills were instigated. Conclusion: It is considered that during the project, the participants of Animal Assisted Intervention with the mediation of dogs have been showing improvement in learning, as well as improvement in speaking, reading and writing skills.

Keywords: Animal Assisted Therapy; Language Development; Learning.

\section{Resumen}

Introducción: Las intervenciones asistidas por animales con la mediación de perros comprende actividades con fines terapéuticos y / o educativos, en las que el perro es el principal mediador. Objetivo: Presentar y analizar los resultados parciales de las actividades desarrolladas en un Proyecto de Investigación y Extensión, realizado en el Colégio de Aplicação da Universidade Federal de Santa Catarina- CA/UFSC, mostrando los beneficios de las intervenciones asistidas por animales con la mediación de perros en el proceso de desarrollo y aprendizaje, especialmente del lenguaje verbal (hablar, leer y escribir) para los estudiantes participantes. Método: Se siguió el enfoque de investigación cualitativa y se realizó el Análisis de Contenido Content de los registros en el campo diario de las actividades desarrolladas. Resultados: Se presentan los resultados de tres acciones llevadas a cabo en el proyecto durante el primer semestre de 2019. El análisis de estas actividades mostró que las habilidades del lenguaje verbal de los estudiantes fueron instigadas. Conclusión: Se considera que durante el proyecto, los participantes de las intervenciones asistidas por animales con la mediación de perros han ido mostrando una mejora en el aprendizaje, así como una mejora en las habilidades de expresión oral, lectura y escritura.

Palabras clave: Terapia Asistida por Animales; Desarrollo del Lenguaje; Aprendizage.

\section{Introdução}

A terapia com cães iniciou-se no Brasil na década de 50, no Estado do Rio de Janeiro. Esta atividade foi inserida no país pela psiquiatra Nise da Silveira, que se tornou pioneira e referência nos estudos das relações emocionais entre pacientes e animais, denominando o cão como coterapeuta. Nise levou animais, principalmente cachorros, e a relação com eles, para dentro dos hospitais psiquiátricos $^{2}$.
Partindo do princípio que o cão pode ser um elemento de referência e um apoio seguro, diferentes estudos ${ }^{2-5}$ apontam os benefícios de sua presença não invasiva em atividades. Destaca-se a transmissão de condições como carinho e confiança dele para o ser humano, nos mais diversos espaços e em diferentes formas de atuação (atividades/ terapias/educação).

De acordo com evidências atuais, a Cinoterapia é denominada como ações com fins terapêuticos e/ou educacionais, nas quais o cachorro torna-se o principal mediador. Tais ações são chamadas 
atualmente de Intervenções Assistidas por Animais (IAA) com a mediação de cães. Ele atua como um agente instigador do trabalho, mediando práticas com objetivos específicos e, consequentemente, impactando nas relações interpessoais e coletivas dos indivíduos envolvidos, de modo a promover a melhora social, emocional, física e/ou cognitiva dos humanos ${ }^{6-8}$.

Quanto à compreensão das IAA com a mediação de cães, o cão atua também como um agente facilitador, de modo que a partir da sua participação sejam desenvolvidas as atividades previamente estabelecidas, visando também à inclusão educacional $^{2}$. Neste sentido, a Educação Assistida por Animais - EAA, mais especificamente, trata-se de uma atividade educativa onde os animais contribuem com o processo de ensino/aprendizagem, uma vez que se tornam uma influência motivadora para o seu desenvolvimento e qualidade ${ }^{5}$.

Neste sentido, desenvolve-se desde 2015, no Colégio de Aplicação da Universidade Federal de Santa Catarina - CA/UFSC - o projeto intitulado "Proposta de atividades mediadas por animais no Colégio de Aplicação" a partir da Cinoterapia, sendo que as atividades desenvolvidas pelo projeto acontecem semanalmente". O referido projeto se propõe a realizar educação e terapia assistida por cães com o objetivo de investigar os benefícios dessas atividades para a qualificação e desenvolvimento das habilidades de linguagem oral e/ou linguagem escrita dos estudantes participantes, que apresentam alteração de linguagem verbal e/ ou dificuldades de aprendizagem, sabendo que a linguagem é importante não só para a organização do pensamento, como também para a compreensão e categorização do mundo que nos cerca9 .

Atualmente, o projeto de IAA com a mediação de cães no CA/UFSC, abrange a terapia e a educação assistida por animais. Estas ações são desenvolvidas por uma equipe transdisciplinar, composta por professoras da Educação Especial e Matemática, acadêmicos de graduação dos cursos de Fonoaudiologia e Pedagogia e, dois cães coterapeutas e seus tutores. O trabalho realizado proporciona aos profissionais, em especial das áreas de saúde e educação, uma visão sobre recursos teórico-práticos disponíveis que podem subsidiar intervenções voltadas às IAA com a mediação de cães.

Ao longo dos cinco anos do projeto, pode-se perceber que as IAA com a mediação de cães auxi- liam na promoção e desenvolvimento da oralidade, leitura e escrita, proporcionando melhora na compreensão, produção oral e consciência fonológica ${ }^{10}$. Nesse sentido, este artigo objetiva apresentar e analisar os resultados parciais das atividades desenvolvidas ao longo de 2019 no projeto, a partir da mediação do cão, apontando os benefícios destas práticas no processo de desenvolvimento e aprendizagem, sobretudo da linguagem verbal (fala, leitura e escrita).

\section{Método}

O projeto que embasa este trabalho se configura como uma ação de pesquisa e extensão, e, para tanto, está registrado no Sistema Integrado de Gerenciamento de Projetos de Pesquisa e de Extensão (SIGPEX-UFSC). Para efetivação de suas práticas no Colégio de Aplicação da UFSC em 2015, foi submetido e aprovado no Colegiado. Além disso, também apresenta aprovação no Comitê de Ética e Pesquisa (CEP) e na Comissão de Ética no Uso de Animais (CEUA-UFSC).

A metodologia deste trabalho apresenta cunho qualitativo, portanto salienta características constitutivas dessa abordagem, como caráter descritivo de investigação, embasando a discussão no processo de desenvolvimento das ações e, não somente no resultado final ${ }^{11,12}$. Desta forma, são analisadas qualitativamente as interações realizadas pelos participantes durante as atividades de IAA com a mediação de cães, assim como, os benefícios destas atividades para o desenvolvimento da linguagem verbal. A análise qualitativa traz contribuições teórico-práticas para os campos da educação e terapia, no qual as pesquisadoras exercem o papel subjetivo de participantes e o papel objetivo de investigadoras.

Os critérios de inclusão dos estudantes para a participação no projeto partem inicialmente do diálogo da equipe com o corpo de docentes do CA/ UFSC, a partir da articulação entre as professoras de Educação Especial, coordenadoras do projeto e os(as) professores(as) de classe comum, que em reuniões de série indicam os estudantes que apresentam as características do público-alvo do projeto: alterações de linguagem oral e/ou dificuldades de aprendizagem na leitura e escrita. A partir da indicação dos (as) professores (as), é realizada uma reunião de cunho elucidativo, onde o projeto é apresentado aos pais e/ou responsáveis dos (as) 
estudantes indicados (as) e então é realizado o convite para participação no projeto.

Os (as) estudantes indicados (as) e que tenham autorização dos responsáveis para participar do projeto, via assinatura do Termo de Consentimento Livre e Esclarecido, participam de avaliações realizadas no CA/UFSC pelas professoras de Educação Especial e bolsistas. As referidas avaliações são compostas por atividades que envolvem fala, leitura, escrita, consciência fonológica, habilidades de atenção e memória.

Um exemplo de atividade utilizada como instrumento no processo avaliativo é o relato oral e escrito de uma narrativa, baseados em uma figura previamente escolhida pelo estudante. Esta avaliação é registrada por meio de gravação de vídeos, utilizados posteriormente tanto para a constatação de possíveis alterações, quanto para a análise contrastiva de fala e componentes da linguagem oral. Após um ano de participação dos estudantes no projeto é realizada nova avaliação, com a finalidade de comparar os resultados pré e pós-participação dos estudantes nas IAA com cachorros.

Atualmente, participam das atividades de IAA com a mediação de cães um total de 20 estudantes, divididos em dois grupos para o trabalho: grupo 1, composto por estudantes dos Anos Iniciais do Ensino Fundamental, e o grupo 2, composto por estudantes dos Anos Finais do Ensino Fundamental e Ensino Médio. Os encontros são realizados semanalmente com participação intercalada entre os grupos, ou seja, na primeira semana do mês frequentam as atividades do projeto os estudantes do grupo 1, na segunda semana participam os estudantes do grupo 2, na terceira participam o grupo 1 novamente, e assim sucessivamente.

Os encontros do projeto têm duração aproximada de uma hora e são realizados logo após o término das aulas do turno vespertino dos estudantes, no CA/UFSC. Para o desenvolvimento das propostas, são utilizados os diversos espaços do Colégio, tanto as salas de aula, quanto as áreas externas disponíveis, proporcionando diversas experiências e atividades, que são planejadas previamente pela equipe e mediadas com o cão.

A observação e o registro em diário de campo de todas as atividades realizadas é um trabalho feito pelas pesquisadoras que compõem a equipe do projeto, catalogadas no acervo de registros do mesmo. Os relatórios semanais dos encontros são descritos com observações gerais da atividade: o objetivo, os recursos necessários, a metodologia e descrição da execução da atividade e os registros das percepções acerca do desenvolvimento individual e coletivo dos estudantes, assim como consta no quadro 1 .

Quadro 1. Exemplo da organização e sistematização de informações pela equipe do projeto.

\begin{tabular}{|c|c|}
\hline \multicolumn{2}{|c|}{ Atividade de figuração } \\
\hline Objetivos & Favorecer figuração, movimentos corporais, linguagem expressiva, concentração e atenção. \\
\hline $\begin{array}{c}\text { Materiais } \\
\text { necessários }\end{array}$ & Brinquedos em miniatura (sapo, galo, cavalo, peixe, leão...) \\
\hline Metodologia & Com auxílio do cão, os estudantes devem procurar uma caixa pelo galpão do Colégio. \\
\hline $\begin{array}{r}\text { Resultados coletivos } \\
\text { Resultados } \\
\text { individuais }\end{array}$ & $\begin{array}{r}\text { Os estudantes apresentaram empatia para ajudar os colegas com dificuldades em realizar a } \\
\text { atividaresentou receio aos latidos do cão, mas com o auxílio das professoras } \\
\text { concluiu a atividade com sucesso. }\end{array}$ \\
\hline
\end{tabular}

Nos diários de campo, os registros consideram as habilidades de fala, leitura, escrita e consciência fonológica, as funções executivas de atenção e memória, a participação e interação social entre os estudantes, além da relação desses com o cão. A dissertação deste artigo apresenta as atividades de IAA com a mediação de cães, desenvolvidas e registradas em diário de campo e os seus benefícios para o processo de desenvolvimento da linguagem verbal dos estudantes.

Bardin $^{1}$ aponta que a análise de conteúdo pode ser também uma análise de significados, pois se ocupa de uma descrição do conteúdo extraído das comunicações e/ou registros e faz a sua respectiva interpretação. Assim, foram selecionados e analisados, a partir desta análise ${ }^{1}$, os registros em 
diário de campo de três propostas de atividades, realizadas ao longo do primeiro semestre de 2019, que têm como principal objetivo a qualificação da linguagem verbal. $\mathrm{O}$ recorte de tempo analisado, compreende os encontros realizados no primeiro semestre de 2019, assim como constam os elementos registrados no quadro 2 .

Quadro 2. Elementos de registro das atividades no recorte de tempo analisado.

\begin{tabular}{|c|c|c|c|c|}
\hline $\begin{array}{c}\text { Atividade } \\
\text { desenvolvida }\end{array}$ & $\begin{array}{c}\text { Grupo } \\
\text { participante }\end{array}$ & Objetivo da atividade & $\begin{array}{c}\text { Cães } \\
\text { mediadores }\end{array}$ & Descrição da mediação do cão \\
\hline $\begin{array}{c}\text { Caixa escondida } \\
\text { e figuração }\end{array}$ & $\begin{array}{c}\text { Grupo 1 e } \\
\text { grupo 2 }\end{array}$ & $\begin{array}{c}\text { Instigar a linguagem } \\
\text { oral, leitura, escrita, } \\
\text { atenção, planejamento } \\
\text { e a memória verbal }\end{array}$ & $\begin{array}{c}\text { Argos e } \\
\text { Rescue }\end{array}$ & $\begin{array}{c}\text { Argos: utilizando o faro, mediar } \\
\text { a procura por uma pequena caixa } \\
\text { escondida no pátio. } \\
\text { Rescue: encontrar os estudantes } \\
\text { escondidos e indicar o local por } \\
\text { meio de latidos }\end{array}$ \\
\hline História oral & Grupo 1 & $\begin{array}{c}\text { Ampliar a } \\
\text { expressividade e } \\
\text { instigar a memória } \\
\text { verbal }\end{array}$ & Teobaldo & $\begin{array}{c}\text { Escolher por meio de biscoitos a } \\
\text { ordem de participação de cada } \\
\text { estudante e assim motivar o } \\
\text { envolvimento dos estudantes }\end{array}$ \\
\hline $\begin{array}{c}\text { Perguntas para } \\
\text { o cão }\end{array}$ & $\begin{array}{c}\text { Grupo 1 e } \\
\text { grupo 2 }\end{array}$ & $\begin{array}{c}\text { Favorecer a produção } \\
\text { oral, habilidades de } \\
\text { atenção/memória e } \\
\text { qualificação da leitura e } \\
\text { escrita }\end{array}$ & Argos & $\begin{array}{c}\text { Expressar por meio de latidos } \\
\text { respostas para as perguntas feitas } \\
\text { pelos estudantes }\end{array}$ \\
\hline
\end{tabular}

\section{Resultados}

A seguir, os resultados de três ações realizadas no projeto durante o primeiro semestre de 2019. A primeira atividade, realizada com ambos os grupos ( 1 e 2), apresentava como objetivo instigar a linguagem oral, leitura e escrita, atenção, planejamento e a memória verbal.

Para a execução desta atividade utilizou-se alguns brinquedos em forma de animais como: sapo, galo, cavalo, peixe, leão e uma caixa de pequeno porte na qual os brinquedos estavam escondidos. Contou-se com a mediação dos cães participantes do projeto, o Argos (6 anos, da raça American Staffordshire) e o Rescue (6 anos, da raça Labrador). Ambos os cães apresentam características de temperamento ${ }^{1}$ ativo, obediente e focado, gostam muito de brincar, estando eufóricos ao interagir com os estudantes e equipe do projeto. Tanto Argos quanto Rescue se encontravam no mesmo ambiente externo da escola juntamente com os estudantes, entretanto participavam da atividade de forma in-

1 Acredita-se que é aceitável discutir a personalidade canina levando em consideração "o padrão usual de comportamento e os seus traços individuais", o que se relaciona diretamente com aspectos biológicos advindos de sua raça, bem como treinamentos recebidos pelo cão ao longo da vida. tercalada, se mantendo parados e próximos ao seu condutor até que fosse sua vez de agir.

Alguns estudantes inicialmente apresentavam receio de se aproximar do cão. Entretanto, ao longo dos encontros, com o apoio dos colegas, passaram a demonstrar avanços com relação à interpessoalidade, apresentando confiança para se aproximar e acariciar o cão, assim como mostra a Figura 1.

Os encontros de IAA com cães desenvolvidos no CA/UFSC exploravam e ressignificavam os diferentes espaços disponíveis. Esta atividade demandava um espaço amplo, de forma que, o estudante em parceria com o cão, pudessem encontrar os objetos escondidos, por este motivo, foi realizada na área externa da escola conhecida como "galpão", que pode ser visualizado na Figura 2.

Inicialmente, realizou-se a explicação sobre a atividade que foi subdividida em duas etapas. $\mathrm{Na}$ primeira etapa, com ajuda do cão Argos, os estudantes deveriam procurar por uma caixa escondida no pátio, que possuía um animal de brinquedo no seu interior. Ao encontrá-la, o estudante deveria memorizar o som que é produzido pelo animal escondido na caixa.

A segunda etapa da atividade baseou-se na utilização da figuração, realizada pelos estudantes para chamar a atenção do cão. A figuração consistia 


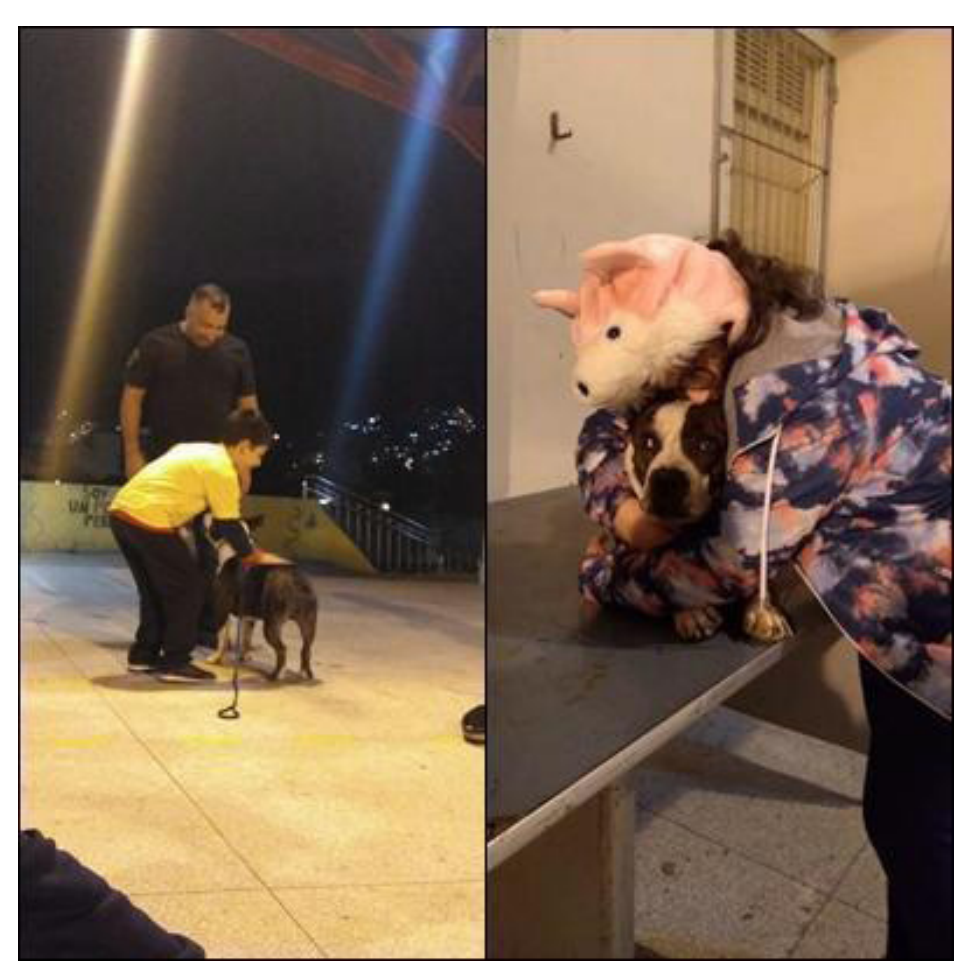

$n$
0
0
1
$\alpha$
$\alpha$

FONTE: ACERVO DO PROJETO

Figura 1. Estudantes dos anos iniciais aproximando-se e acariciando o cão.

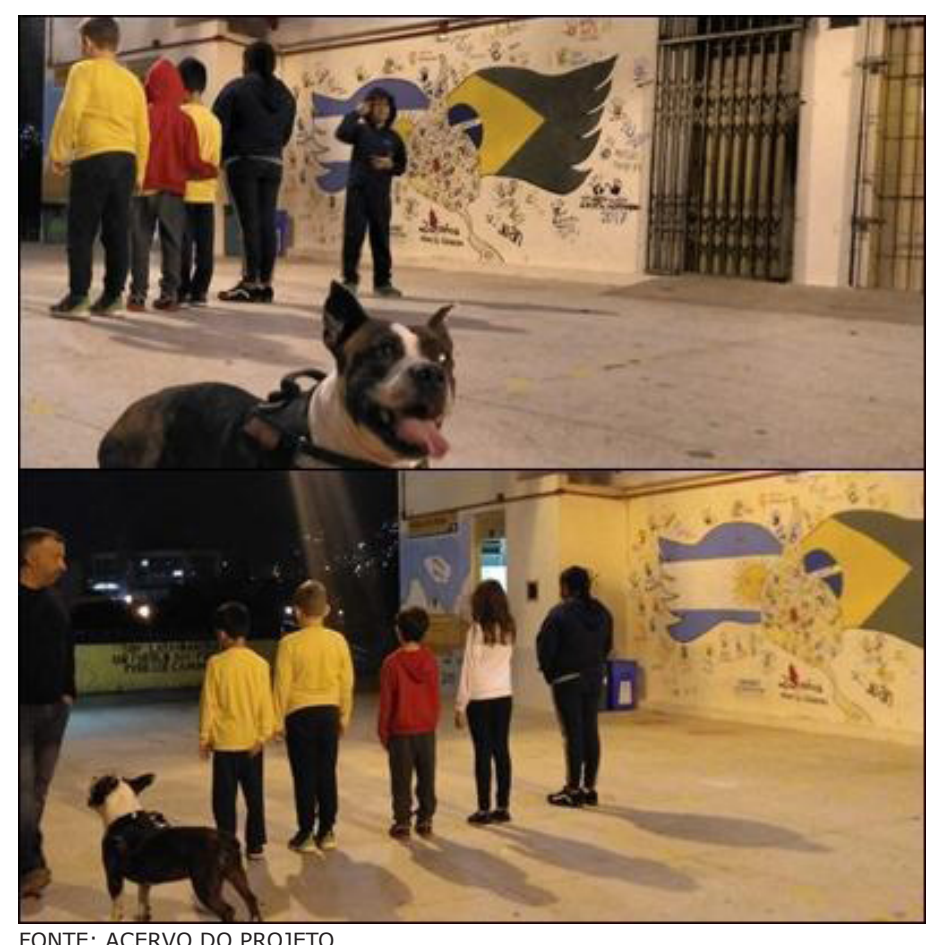

Figura 2. Estudantes dos anos iniciais do Ensino Fundamental realizando a atividade na área externa do CA/UFSC. 
em realizar uma série de movimentos corporais e sons, no intuito de direcionar a atenção do cachorro para quem estava realizando a atividade.

Assim, para realizar a figuração, os estudantes deveriam imitar o som e os movimentos do animal encontrado na caixa e chamar atenção do cão Rescue. Em seguida, com um brinquedo de odor reconhecido pelo faro do cachorro, o estudante deveria esconder-se em algum lugar no galpão de forma que ele pudesse encontrá-lo. No momento em que o cão encontrasse o estudante, começaria a latir, cabendo a criança contar dez latidos e lançar o brinquedo o mais longe possível, para o cão buscar como forma de premiá-lo.

Durante a atividade, dois estudantes se destacaram por ajudar os colegas que apresentaram maior dificuldade em manter a atenção concentrada. Estes estudantes, demonstrando empatia e um perfil comunicativo mais hábil durante as atividades, proporcionaram a qualificação nas interações do grupo e na intenção comunicativa dos colegas que apresentavam dificuldade nesse aspecto. No que se refere à oralidade, de modo geral, os estudantes demonstraram bom desempenho.

Os estudantes que apresentavam transtorno fonológico ${ }^{13}$ manifestaram dificuldades na pronúncia dos sons dos animais, por exemplo: "cocorricó" ao invés de "cocoricó" e "cloclodilo" ao invés de "crocodilo". Ao apresentarem estas dificuldades, os estudantes foram auxiliados pela equipe do projeto, principalmente as acadêmicas do curso de Fonoaudiologia, que realizaram a orientação e acompanhamento para a pronúncia correta dos fonemas.

A segunda atividade, realizada com o grupo 1, composto por estudantes dos Anos Iniciais do Ensino Fundamental, apresentava como propósito, a elaboração de uma história oral coletiva, objetivando qualificar a linguagem oral, ampliar a expressividade e instigar a memória verbal. De forma individual, cada estudante deveria criar oralmente um trecho da história, agregando um objeto e o animal, encontrado na primeira atividade descrita. A ordem de participação na história foi mediada pelo cão Teobaldo ( 7 anos da raça pequinês, temperamento tranquilo, passivo, paciente e brincalhão), que escolhia quem iria começar e/ou seguir a história, fator motivador para o envolvimento dos estudantes.

O quadro 3, ilustra o resultado final da história coletiva criada, evidenciando a transcrição das contribuições de cada estudante. Assim como, a forma como foram desenvolvendo a narrativa, inserindo os objetos e animais encontrados na atividade anterior, com o cão Argos.

Quadro 3. Elementos da história coletiva elaborada pelos estudantes.

\begin{tabular}{|c|c|c|c|}
\hline Estudante & Objeto & Animal & Transcrição da contribuição para a história \\
\hline Estudante 1 & Chapéu & Cavalo & $\begin{array}{l}\text { Era uma vez um cavalo cowboy chamado Senhor Cavalo. Ele começou a andar em uma } \\
\text { vila que não conhecia, então viu um chapéu. }\end{array}$ \\
\hline Estudante 2 & Livro & Peixe & $\begin{array}{l}\text { O cavalo encontrou um peixinho que estava mergulhando nessa vila. Foi quando de } \\
\text { repente apareceu um cavalo marinho que trazia um livro chamado "livro peixe". O peixinho } \\
\text { perguntou "por que você está pegando esse livro?" então o cavalo marinho respondeu "é } \\
\text { porque eu preciso levar o livro pra casa para ler o livro". O peixinho ficou triste porque não } \\
\text { queria pegar o livro, mas o levou pra casa mesmo assim. Quando ele chegou em casa, } \\
\text { lá tinham dois peixes: o pai e a mãe, eles ficaram muito unidos e felizes em encontrar o } \\
\text { peixe com o livro. Eles abraçaram o peixe e o livro e foram dormir. }\end{array}$ \\
\hline Estudante 3 & Apontador & Pato & $\begin{array}{l}\text { No outro dia, quando o peixe acordou, ele percebeu que havia se transformado em pato. } \\
\text { Ele não sabia o que tinha acontecido, foi quando encontrou um apontador da verdade e } \\
\text { descobriu que quem foi o culpado por tudo isso era um cavalo. Então se revelou o mistério: } \\
\text { o culpado nessa história toda era o Senhor Cavalo. }\end{array}$ \\
\hline Estudante 4 & Pente & $\begin{array}{l}\text { Grilo/ } \\
\text { gafanhoto }\end{array}$ & $\begin{array}{l}\text { O pato também era mágico então fez uma mágica e transformou o cavalo em grilo/ } \\
\text { gafanhoto. Foi quando o grilo/gafanhoto perguntou: "Como vou pentear o meu cabelo, } \\
\text { se não tenho mais cabelo?" }\end{array}$ \\
\hline Estudante 5 & Óculos & Sapo & $\begin{array}{l}\text { O senhor grilo caiu em um buraco e dentro do buraco encontrou um sapo maluco que } \\
\text { era cientista. Então o sapo maluco cientista jogou um pó em cima do grilo. Ele olhou } \\
\text { para cima e viu escrito que lá era a arena } 51 \text {, ela era proibida. Foi quando ele pegou uma } \\
\text { lanterna e voltou lá, encontrou um livro que queria matar ele. O sapo cientista correu para } \\
\text { seu laboratório e o peixe estava lá, ele queria transformar o peixe com um óculos que } \\
\text { atirava em um monte de coisas. De repente o grilo correu com a máquina de transformar } \\
\text { animais em outros animais, aí ele conseguiu transformar com o óculos atirando em tudo } \\
\text { o sapo cientista em um pato. }\end{array}$ \\
\hline Estudante 6 & Cola & Pato & O sapo cientista ficou muito bravo e transformou o patinho em uma cola bastão. \\
\hline Estudante 7 & Microfone & Galo & $\begin{array}{l}\text { A cola bastão jogou um microfone mágico e transformou o sapo cientista em um galo. } \\
\text { Então ele passou a viver como em galo, em sítio fazenda com suas amigas galinhas. O } \\
\text { microfone mágico explodiu. }\end{array}$ \\
\hline
\end{tabular}


Ao longo da construção da história oral coletiva, puderam ser trabalhados e favorecidos diversos aspectos, que qualificaram o desenvolvimento da linguagem verbal dos estudantes, como: a expressividade facial e corporal, o repertório criativo e imaginário, a oralidade, a entonação da voz. Motivados pela presença do cão Teobaldo que escolhia quem seria o próximo a continuar a história, os estudantes demonstraram preocupação com a coerência na continuidade do que estava sendo contado, o que proporcionou a esses a manutenção da atenção concentrada e instigação da memória verbal no momento em que os colegas estavam falando, assim como planejamento e organização do pensamento para contar a sua parte, de forma que todos pudessem compreender, assim como mostra a Figura 3.

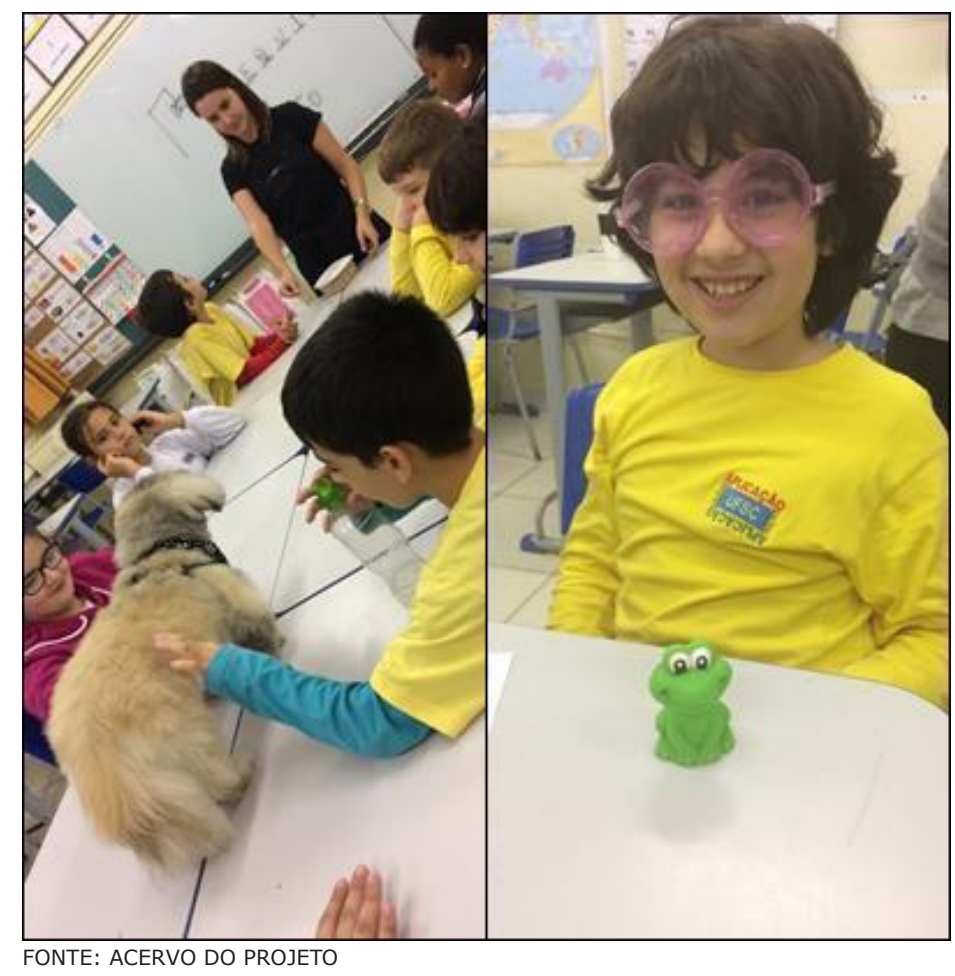

Figura 3. Estudantes dos anos iniciais realizando a atividade.

A terceira atividade, realizada com ambos os grupos, teve como objetivo favorecer a produção oral, favorecer as habilidades de atenção e memória e a qualificação da leitura e escrita. Para seu desenvolvimento foram utilizadas fichas de perguntas, onde os próprios estudantes produziram questões direcionadas ao cão Argos, com intuito de elaborar, escrever e ler suas perguntas a ele. Logo após, o estudante deveria jogar o brinquedo e apresentar para o cachorro um dos comandos já aprendidos, por exemplo.

Inicialmente os alunos escreveram as perguntas sobre curiosidades que tinham a respeito do Argos. Alguns estudantes sentiram dificuldade em pensar nas possíveis perguntas, mas com auxílio das professoras da Educação Especial e das acadêmicas do curso de Fonoaudiologia, conseguiram cumprir a tarefa. Em seguida, os estudantes direcionaram-se para a área externa da escola, onde foi dada sequência na atividade, assim como mostra a Figura 4.

Por meio de sorteio, definiu-se a ordem em que cada estudante deveria ler sua pergunta ao cão, todos estavam bastante animados para o momento em que seriam chamados. A seguir, apresenta-se o quadro $4 \mathrm{com}$ as perguntas elaboradas pelos estudantes que estavam presentes no encontro em que a atividade foi desenvolvida. 


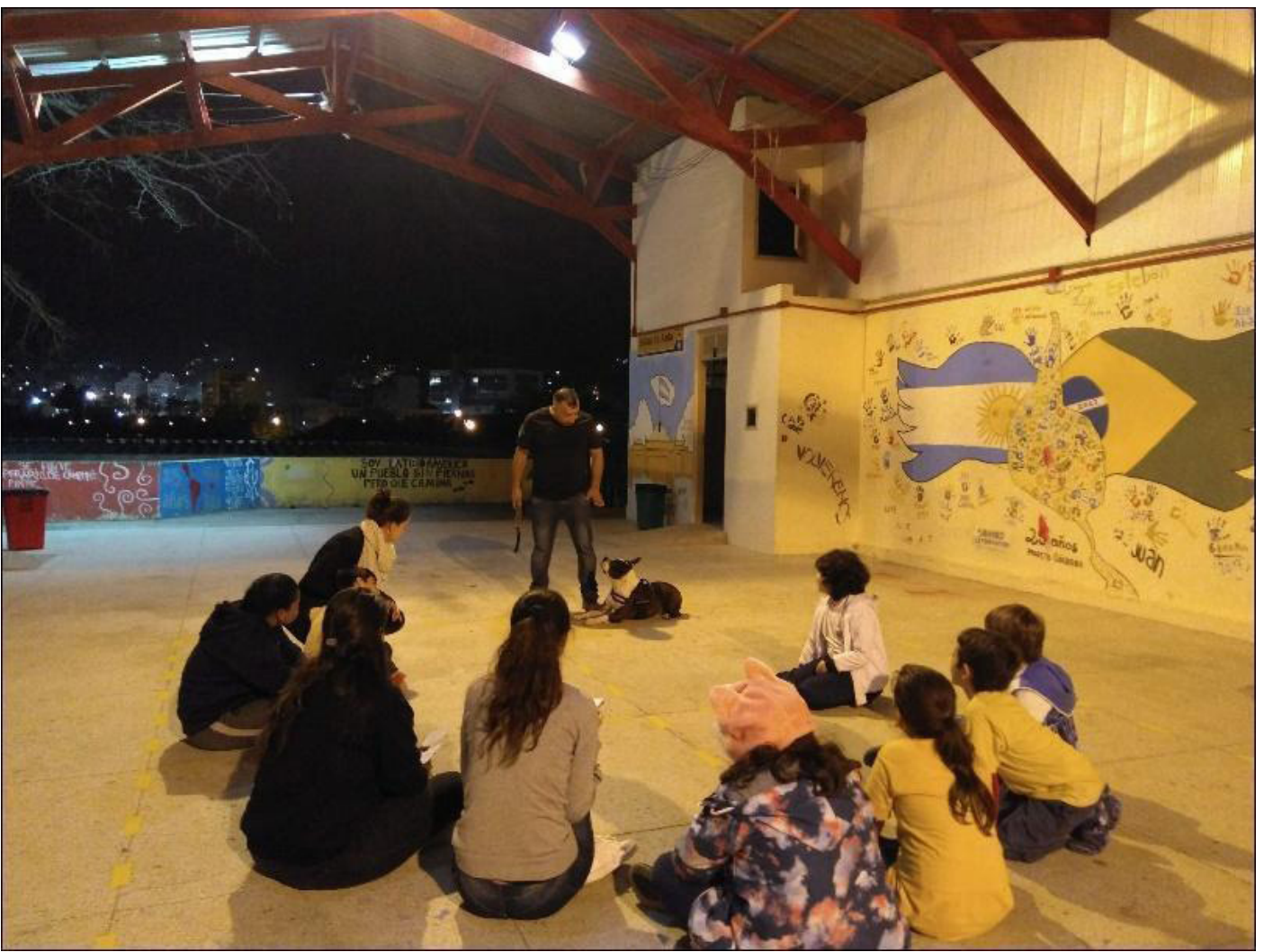

FONTE: ACERVO DO PROJETO

Figura 4. Estudantes dos anos iniciais realizando a atividade.

Quadro 4. Perguntas elaboradas pelos estudantes para o cão.

\begin{tabular}{|c|c|}
\hline Estudante & Pergunta para o cão \\
\hline Estudante 1 & Quantos anos você tem? \\
\hline Estudante 2 & Que cor você gosta? \\
\hline Estudante 3 & $\begin{array}{c}\text { Você gosta de mim? } \\
\text { Você gosta de ração/água? }\end{array}$ \\
\hline Estudante 4 & $\begin{array}{c}\text { Meus amigos são bonitos? } \\
\text { O cachorro late? }\end{array}$ \\
\hline Estudante 5 & $\begin{array}{c}\text { De onde você veio? } \\
\text { Qual país? }\end{array}$ \\
\hline Estudante 6 & Você tem namorada? \\
\hline Estudante 7 & Você fala quantas línguas? \\
\hline Estudante 8 & Você gosta de brincar? \\
\hline
\end{tabular}

Os estudantes mostraram-se interessados nas respostas do cão, que expressava com um latido a representação do "sim" e, com silêncio, a representação do "não". As respostas que exigiram números, como, por exemplo, a idade do cão e as línguas que compreende, foram registradas pelo número de latidos de Argos, contados pelos estudantes. Todas as reações do cão às perguntas dos participantes foram conduzidas pelos comandos do tutor. Alguns alunos manifestaram dificuldade de compreensão e em manter a atenção concentrada, em especial os estudantes 4 e 8 . Em contrapartida, esses apresentaram facilidade para memorizar as perguntas e realizar a leitura para o cão. Durante a realização da atividade, os estudantes foram orientados a respeito da importância do silêncio e do autocontrole do seu comportamento, para que o cão pudesse entender e obedecer aos comandos dados.

Embora cada uma das três atividades tivesse configurações diferenciadas, manteve-se o objetivo de trabalhar a linguagem verbal e desenvolver e/ou aprimorar aspectos sociais, emocionais e cognitivos dos estudantes envolvidos. Diante das observações e dos registros em diário de campo, foi possível identificar, também, que as IAA com a mediação de cães abarcam e permitem trabalhar aspectos mais amplos que perpassam as aprendizagens de- 
senvolvidas no ambiente escolar, como o trabalho transdisciplinar, as interações sociais e a empatia.

\section{Discussão}

As IAA mediadas por animais no âmbito educacional podem motivar os estudantes durante as atividades desenvolvidas na escola, por exemplo, na leitura e escrita ${ }^{3}$. São diversos os benefícios destas intervenções e o cão pode ser um importante mediador para o seu desenvolvimento afetivo, social e cognitivo ${ }^{14,15}$.

A primeira atividade relatada envolveu aspectos de figuração, movimentação corporal, atenção e linguagem expressiva. Existe uma forte conexão entre habilidades motoras e os desenvolvimentos da linguagem, sendo assim, os autores recomendam a participação de cães em atividades que busquem promover o desenvolvimento da linguagem oral das crianças ${ }^{3}$. Por esse motivo, atividades que envolvam este tipo de habilidade favorecem o desenvolvimento dos estudantes público-alvo do projeto.

Neste sentido, afirma-se que crianças com dificuldades linguísticas podem possuir habilidades motoras deficitárias ${ }^{16}$. Pressupõe-se, então, que as habilidades motoras e de fala estão ligadas aos centros de controle do cérebro, destacando, assim, a importância da consciência dos movimentos motores durante a atividade, como favorecedora do desempenho de fala ${ }^{17}$.

Percebeu-se que, inicialmente, alguns estudantes apresentaram receio aos latidos do cão durante a contagem. Porém, no decorrer da atividade, com auxílio da equipe do projeto e colegas, esses foram se aproximando e desenvolvendo o vínculo afetivo com o animal, conseguindo concluir a sua realização com sucesso. Assim, a aproximação de crianças e animais desenvolve uma série de benefícios, como facilitar e mediar a relação entre educador ou terapeuta e participantes das IAA, promovendo aos estudantes aprender novas habilidades de forma eficiente ${ }^{18,19}$.

O Transtorno Fonológico, assim como a definição descrita no DSM-5, envolve os distúrbios fonológicos e de produção/articulação da fala, comprometendo a inteligibilidade da fala do sujeito ${ }^{20}$. Com relação a estes aspectos, foi possível observar exemplos diante da fala de alguns estudantes, manifestação das dificuldades na pronúncia dos sons dos animais como, por exemplo, "cocorricó" ao invés de "cocoricó", a pronúncia de "cloclodilo" ao invés de "crocodilo", entre outras. Os estudantes contaram com a mediação das acadêmicas de graduação em Fonoaudiologia e o incentivo do cão durante a atividade.

Sobre a segunda atividade relatada, percebeu-se que os estudantes se mostraram empolgados e organizados na atividade, além de apresentarem muita criatividade. A história é um gênero de texto que apresenta princípios de constituição, entre eles se encontra a organização linguística e seus componentes estruturais ${ }^{21}$.

Percebe-se que a história elaborada pelos estudantes apresenta manutenção dos personagens, de modo que a preocupação com a inserção dos objetos e animais anteriormente encontrados é evidente e ocorre de forma coerente e criativa. Como por exemplo, nota-se a inserção do animal "pato" e objeto "apontador", nos eventos da história, no trecho criado pelo estudante 3 :

No outro dia, quando o peixe acordou, ele percebeu que havia se transformado em pato. Ele não sabia o que tinha acontecido, foi quando encontrou um apontador da verdade e descobriu que quem foi o culpado por tudo isso era um cavalo [...].

Artigos científicos ${ }^{16,17,22}$ descrevem a associação entre a imaginação e o desenvolvimento das habilidades verbais. Este aspecto vinculado ao crescente autocontrole e atenção para realizar a atividade com o cão, configuram-se como um auxílio na minimização das dificuldades relacionadas ao ritmo de fala, componente pragmático da linguagem e ainda, colaboram para melhor compreensão e maior desempenho nas atividades. Em âmbito geral, percebe-se que no desenvolvimento de ações como a atividade 2 , houve uma qualificação na expressão oral e escrita dos estudantes.

A terceira atividade envolvia a produção escrita e realização de leitura para o cão. A leitura assistida por cães visa a compreensão do texto que está sendo lido e a comunicação interativa em um contexto de leitura mais segura e confortável, uma vez que, ocorre com a mediação de um cão treinado, altamente sociável e com uma natureza sem julgamento, tornando o ambiente de aprendizado mais favorável para estudantes que apresentam dificuldades de leitura e escrita ${ }^{19,23,24}$.

Mesmo tendo iniciado a atividade com agitação, aos poucos, os estudantes foram demonstrando autocontrole e flexibilidade cognitiva, pois estavam motivados a fazer a pergunta, jogar o brinquedo 
e dar comandos para o Argos. Estudos sugerem que os cães tornam-se socialmente atraentes para crianças que apresentam déficits de comunicação, de modo que sua presença torna-se um elemento de motivação para a aprendizagem ${ }^{4,25}$.

Os registros da atividade apresentaram resultados que ratificam os benefícios das IAA mediadas por cães para crianças que demonstraram dificuldade de iniciar interações, problemas de atenção e emocionais, particularmente na leitura de instruções que exigem que elas falem ${ }^{26,27,28}$. Além disso, conforme revelado por estudos recentes, a incorporação de cães treinados em programas de leitura pode ser particularmente benéfica para essas crianças ${ }^{23}$.

Evidencia-se que as três atividades apresentadas neste estudo apresentaram inúmeros benefícios aos estudantes, entre eles o favorecimento do processamento cognitivo das informações linguísticas, influenciando diretamente na qualificação da linguagem verbal ${ }^{29,30}$. A presença do cão tornou a atividade mais significativa, sendo que também promoveu benefícios para as funções executivas, como memória verbal, atenção concentrada e autocontrole dos estudantes, ao refletir e analisar os comandos e as respostas apresentadas pelo cão, desta forma motivando a interação e favorecendo a qualificação de diferentes habilidades e aprendizagens ${ }^{27,28}$.

\section{Considerações Finais}

Considera-se que no decorrer do projeto, os participantes das IAA com a mediação de cães demonstraram aperfeiçoamento da fala, leitura e escrita. Além disso, percebeu-se que com o desenvolvimento das atividades, os estudantes também obtiveram estímulos relacionados à memória e atenção. Os favorecimentos de habilidades relacionadas à linguagem verbal ganharam espaço com o desenvolvimento das práticas que rotineiramente não são realizadas, tanto na escola, como em terapias convencionais, por exemplo, a elaboração e contação de histórias. Estas atividades foram significadas pela presença do cão, que atuou como o principal mediador e, proporcionou, por meio do vínculo afetivo estabelecido, ampliação das habilidades trabalhadas com os estudantes.

Dentre outros benefícios, encontra-se ainda o aumento na autoestima e na qualidade das interações, intensificadas pela colaboração e participação efetiva das atividades com o cão. Desta forma, observou-se uma melhora predominantemente significativa na linguagem oral, emocional e educacional.

Em suma, percebeu-se ainda, que há uma ampla diversidade de práticas quanto às IAA com a mediação de cães, realizada por diversos profissionais das áreas da saúde e educação. Porém, ainda há uma carência de estudos científicos abordando esta temática, fazendo-se necessário, portanto, ampliar o número de pesquisas no Brasil, que abordem as IAA com cães e analisem cientificamente os benefícios dessas para os seres humanos.

\section{Referências}

1. Bardin L. Análise de conteúdo. São Paulo: Edições 70; 2011. 2. Fidler MD. A educação mediada por animais como atividade desenvolvente no processo de aprendizagem de estudantes com deficiência. [dissertação]. Santa Maria: Universidade Federal de Santa Maria - UFSM; 2016.

3. Gee NR, Harris SL, Johnson KL. The Tole of therapy dogs in speed and accuracy to complete motor skills tasks for preschool children. Anthrozoös [Internet]. 2015 [acesso em 2020 set 8]; 20(4): 375-86. Disponível em: https://www.tandfonline.com/ doi/abs/10.2752/089279307X245509

4. Prothmann AC. Ettrich C, Prothmann S. Preference and responsiveness to people, dogs and objects in children with autism. Anthrozoös [Internet]. 2009 [acesso em 2020 set 8]; 22(2): 161-71. Disponível em: https://www.tandfonline.com/ doi/abs/10.2752/175303709X434185

5. Martins MF. Animais na escola. In: Dotti J. Terapia \& Animais. Osasco: Noética; 2006.

6. Duque JAV. Actividades y terapia asistida por animales desde la mirada del Modelo de Ocupación Humana. Revista Chilena de Terapia Ocupacional [Internet]. 2011 [acesso em 2020 set 8]; 1(11): 29-36. Disponível em: https://revistaterapiaocupacional. uchile.cl/index.php/RTO/article/view/17080

7. Dotti J. Terapia e animais. São Paulo: Noética; 2005.

8. Garcia PM, Batomé PS. Da Domesticação à Terapia: o Uso de Animais para Fins Terapêuticos. Interação em Psicologia [Internet]. 2008 [acesso em 2020 set 8]; 12(1): 165-7. Disponível em: https://revistas.ufpr.br/psicologia/article/view/9676

9. Saussure F. Curso de lingüística geral. São Paulo: Cultrix; 2002.

10. Camargo RG, Potgurski DS, Sarzi LZ, Diniz CF, Weber FCS. Cinoterapia: práticas transdisciplinares em Educação e Fonoaudiologia. In: Monteiro SAS. A educação no Brasil e no mundo. 5. Ponta Grossa: Atena; 2020. P. 39-48.

11. Gil AC. Como elaborar projetos de pesquisa. São Paulo: Atlas; 2010.

12. Silva, MJP. Percebendo o ser humano além da doença- o não verbal detectado pelo enfermeiro. Nursing (São Paulo) [Internet]. 2001 [acesso em 2020 set 8]; 4 (41): 14-20. Disponível em: https://pesquisa.bvsalud.org/portal/resource/ pt/bde-11080 
13. Costa PP, Mezzomo CL, Soares MK. Verificação da eficiência da abordagem terapêutica miofuncional em casos de desvio fonológico, fonético e fonético-fonológico. Rev. CEFAC [internet]. 2013 [acesso em 2020 set 8] 15(6): 1703-11. Disponível em: https://www.scielo.br/pdf/rcefac/v15n6/54-11. pdf

14. Caetano, EC. As Contribuições da TAA - Terapia Assistida por Animais a Psicologia. [Trabalho de Conclusão de Curso]. Criciúma: Universidade do Extremo Sul Catarinense - UNESC; 2010.

15. Lima CM, Nunes DM, Krug DM, Nobre M. Educação assistida por animais: estratégia promissora no âmbito escolar. Revista Brasileira de Educação e Saúde [Internet]. 2018 [acesso em 2020 set 7]; 8(1): 54-7. Disponível em: https://www.gvaa. com.br/revista/index.php/REBES/article/view/5946

16. Marton K. Imitation of body postures and hand movements in children with specific language impairment. Journal of Experimental Child Psychology [Internet]. 2009 [acesso em 2020 set 8]; (102): 1-13. Disponível em: https://www.ncbi.nlm. nih.gov/pmc/articles/PMC2584158/

17. Vukovic M, Vukovik I, Stojanovik V. Investigation of language and motor skills in Serbian speaking children with specific language impairment and in typically developing children. Research on developmental disabilities [Internet]. 2010 [acesso em 2020 set 8]; 31: 1633-44. Disponível em: https://www.sciencedirect.com/science/article/abs/pii/ S0891422210000995

18. Ferreira JM. A Cinoterapia na APAE/SG: um estudo orientado pela teoria bioecológica do desenvolvimento humano. Conhecimento \& amp. Diversidade [Internet]. 2012 [acesso em 2020 set 8]; (7): 98-108. Disponível em: https://revistas. unilasalle.edu.br/index.php/conhecimento_diversidade/article/ view/626

19. Squilasse AF, Squilasse JFT. Intervenções assistidas por animais: considerações gerais. Educação Continuada em Medicina Veterinária e Zootecnia do CRMV-SP. São Paulo: Conselho Regional de Medicina Veterinária [Internet]. 2018 [acesso em 2020 set 8]; 16(2): 30-5. Disponível em: https:// www.revistamvez-crmvsp.com.br/index.php/recmvz/article/ view/37778

20. American Psychiatric Association - DSM-5: manual diagnóstico e estatístico de transtornos mentais. Porto Alegre: 2014.

21. Spinillo AG, Martins RA. Uma análise da produção de histórias coerentes por crianças. Psicologia Reflexão e Crítica [Internet]. 1997 [acesso em 2020 set 8]; 10(2): 219-48. Disponível em: https://www.scielo.br/scielo.php?pid=S010279721997000200004\&script $=$ sci_abstract\&tlng=pt

22 . Toomela A. Drawing as a verbally mediated activity: a study of relationships between verbal, motor, and visuospatial skills and drawing in children. International Journal of Behavioral Development [Internet]. 2002 [acesso em 2020 set 8]; 26: 134-247. Disponível em: http://citeseerx.ist.psu.edu/viewdoc/ download?doi=10.1.1.122.3660\&rep=rep1\&type $=$ pdf

23. Suk-chun F. Canine-assisted reading programs for children with special educational needs: rationale and recommendations for the use of dogs in assisting learning. Educational Review [Internet]. 2017 [acesso em 2020 set 8]; 69(4): 435-50. Disponível em: https://www.tandfonline.com/doi/abs/10.1080 /00131911.2016.1228611? journalCode $=$ cedr20
24. Petenucci AL. Efeitos da Educação Assistida por Animais na leitura em um grupo de estudantes do Ensino Fundamental. [dissertação]. Pontifícia São Paulo: Universidade Católica de São Paulo - PUC/SP; 2018.

25. Celani, G. Human Beings, Animals and Inanimate Objects: What do People with Autism Like? SAGE [Internet]. 2002 [acesso em 2020 set 8]; 6 (1): 93-102. Disponível em: https:// journals.sagepub.com/doi/abs/10.1177/1362361302006001007

26. Berget B, Ekeberg O, Pedersen, Braastad B. AnimalAssisted therapy with farm animals for persons with psychiatric disorders: effects on anxiety and depression, a randomized controlled trial. Occupational Therapy in Mental Health [Internet]. 2011 [acesso em 2020 set 8]; 27(1): 50-64. Disponível em: https://www.ncbi.nlm.nih.gov/pmc/articles/PMC2323374/

27. Oliveira GR, Ichitani T, Cunha MC. Atividade Assistida por Animais: efeitos na comunicação e interação social em ambiente escolar. Distúrb Comun [Internet]. 2016 [acesso em 2020 set 7]; 28(4): 759-63. Disponível em: https://revistas.pucsp.br/dic/ article/view/28017

28. Machado JAC, Rocha JR, Santos LM, Piccinin A. Terapia Assistida por Animais (TAA). Revista Científica Eletrônica de Medicina Veterinária [Internet]. 2008 [acesso em 2020 set 8]; 5(10): 7. Disponível em: http:// faef.revista.inf.br/imagens_arquivos/arquivos_destaque/ yBDakPBzygjagIw_2013-5-28-12-0-12.pdf

29. Pagliarin KC. Abordagem contrastiva na terapia fonológica em diferentes gravidades do desvio fonológico [dissertação]. Santa Maria: Universidade Federal de Santa Maria - UFSM; 2009.

30. Potgurski DS, Sarzi LZ, Camargo, RG. Cinoterapia: práticas transdisciplinares para qualificação do atendimento em Educação Especial. Colóquio Internacional de Educação Especial e Inclusão Escolar [Internet]. 2019 [acesso em 2020 set 8]; 1: 11. Disponível em: https://proceedings.science/ cintedes-2019/papers/cinoterapia--praticas-transdisciplinarespara-a-qualificacao-do-atendimento-em-educacao-especial 